\title{
Tar Balls Collector for Mechanical Recovery in Combating Oil Spill on the Marine Environment
}

\author{
Cokorda Prapti Mahandari ${ }^{1, a}$, Mohamad Yamin ${ }^{2, b}$ dan Septian Andri Asandi ${ }^{3, c}$ \\ ${ }^{1,2,3}$ Faculty of Industrial Technology Gunadarma University, Indonesia \\ acoki@staff.gunadarma.ac.id, ${ }^{b}$ mohay@staff.gunadarma.ac.id
}

Keywords: oil spill, tar balls collector, mechanical recovery

\begin{abstract}
The impacts of oil spill on water pollution are more fatal than on the mainland because the spread of pollutants is larger and more massive. Various techniques are available for dealing with oil spill in the sea. However they turn out to be less effective in combating oil spill in the form of tar balls. Meanwhile, currents, tides and wind can carry tar balls far from the spill location. Therefore, emergency response must be deployed right away. Tar balls are finally collected manually by empowering fishermen in a short time which is quite difficult to be done. This paper discussed a tar balls collector that was designed based on net fishing tool and that it will be simply mounted on the side vessel or combating ship. Tar balls collector consists of several components including the clamp, long support, pulley, rings, frame of the net and net. Structure analysis of the long support of this tool was carried to determine force reaction and stress resultant. This equipment was designed to collect faster and more tar balls, hence reducing the impact of pollution on the marine environment.
\end{abstract}

\section{Introduction}

The oil spill in the marine environment can interfere the organisms that live on or around the surface and under water. The feather of birds and marine animals including fish can become covered by oil so that most of them would not survive if it people did not clean them. An oil spill can block the sunlight that vegetation needs for photosynthesis. The oil spill could also damage part of the food chain including human food resources [1].

Oil spill can end in closed beaches and harbours. This affects transportation, fishing and tourism sector. Moreover, there are some areas in the marine environment that are more sensitive to oil pollution than others. Mangroves, marsh and coral reefs are more sensitive than sandy beaches and sea-grass bed. Currents, tides and wind can carry the oil far from the spill location causing damage to the plants, birds and marine animals along the way.

Combating the oil spill in the waters should be focused on separating oil from water. Current research in separating oil from water is the application of the concept of micro filtration using membranes made from Polyvinylidenefluoride [2] or a membrane of polysulfone [3], the process of elektrofluotation [4] and the use of magnets and nano-technology [5]. These concepts have not been applied to the emergency oil spill incident. They are still at an experimental level in the laboratory.

Oil spill on the marine environment came from many different sources, i.e drilling operation includes discharges and accident spill from oil field operation, transportation and transfer of oil, routine maintenance and other ship operation. The characteristics of oil such as density, volatility, toxicity and viscosity are also different and they influence the cleaning methods that will be used.

Characteristics of crude oil from wells in the platforms in Indonesia vary. The densities of oil range from $0,85 \mathrm{~cm}^{3} / \mathrm{gr}$ to $0,9 \mathrm{~cm}^{3} / \mathrm{gr}$. Some wells have oil that tend to be on solid state at room temperature. Oil spill due to offshore driling and exploration some time occured and oil became tar balls floating in the ocean as shown on Fig. 1. Among the methods to clean up the oil spill such as bioremediation, chemical dispersant, skimmers, boom and sorbent, only oil boom or pneumatic oil barrier showed the potential but in fact it failed. Oil booms were only effective on very calm water 
[6]. Based on experience, the tar balls collected involved fishermen to collect the tar balls manually. Sometimes looking for fishermen in a very short time was not easy as collecting the tar balls should be done as soon as possible in order to emergency response. For the sake of efficiency and effectiveness in combating oil spills at sea, especially tar balls, then a tar balls collector was designed as a mechanical equipment derived from traditional method of fishing using nets. The equipment will simply be mounted on the side of the ship.

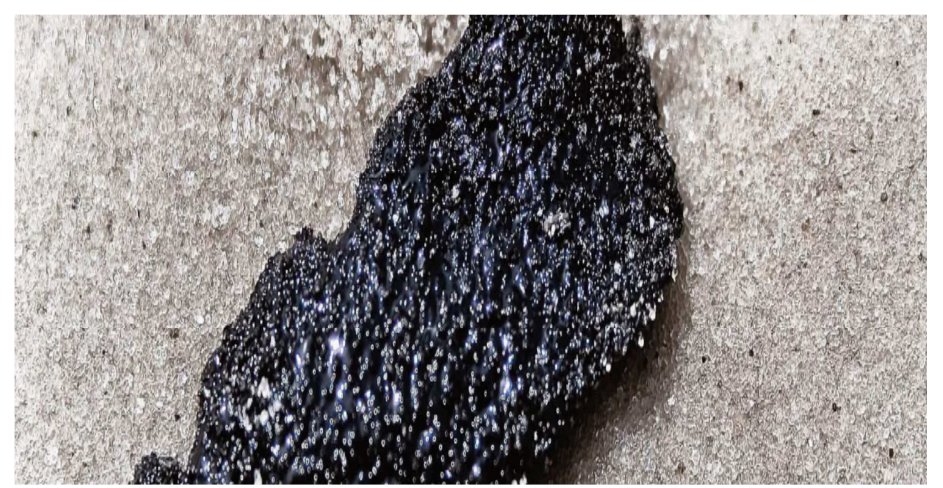

Figure 1. Tar balls

\section{Research Method}

A tar balls collector was designed based on traditional fishing tool using a net. The tar balls collector was designed to operate at sea, so this tool should be made from high resistant corrosion material and high yield stress but low price. The material for this tool was stainless steel of AISI grade $316 \mathrm{~L}$. This tool is also designed to be unloaded from the ship and then folded when no oil spill occurred. The tar balls collector consists of several components including the clamp, long support, pulley, ring, frame of the net and the net.

The main component is the long support to support the net. The sketch of the free body diagram of the long support was drawn. It showed the external force and the support reaction. As more than three support reactions exist, the structure could not be determined from the three equilibrium conditions. The structure is called statically indeterminate. There were four unknown reactions that made the structure to be one degree of static indeterminacy. It can be solved by applying the mechanic of material i.e. consistent deformation methods. Finally stress resultant of the structure was calculated particularly normal force, shear force and the bending moment.

\section{Result and Discussion}

A tar balls collector was designed with refer to the traditional fishing tool using a net. However the tar balls collector was completed by a pulley. Fig. 2 shows the tar balls collector design and Fig 3 . illustrates the component of tar balls collector starting from number 1 is clamp then long support, pole handle, net frame, ring hook, ring nets, ring pulley, clamp and net respectively. There are two different clamps. The bigger clamp was incorporated with hinge to hang and folded the long support on the side of vessel. The two smaller clamps connected the two pole handle and the long support. The length of long support is $4 \mathrm{~m}$ and is made from hollow cylinder with the outside diameter of $3,175 \mathrm{~cm}$ and the thickness of $2,5 \mathrm{~mm}$. There was a hinge in the middle of the long support so that the long support could be folded. Pole handle was a slender bar where the net frame position can be adjusted by the ring pulley. Net frame was connected to the net using 24 rings net. The net was a conical net and the grid was $5 \mathrm{~mm}$.

Mechanical analysis was focused on the long support that supported the net. Technical drawing of this component was shown on Fig. 4. Free body diagram of this system was drawn as on Fig 5. It based on the external forces that calculated using Eq. 1 to Eq. 4 


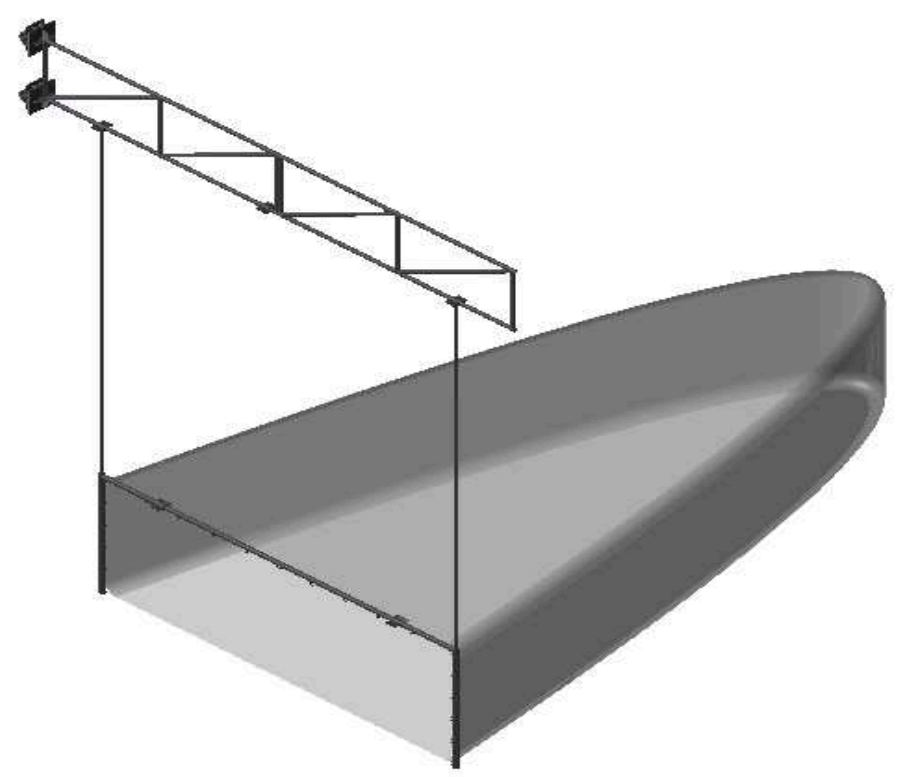

Figure. 2. Tar balls collector
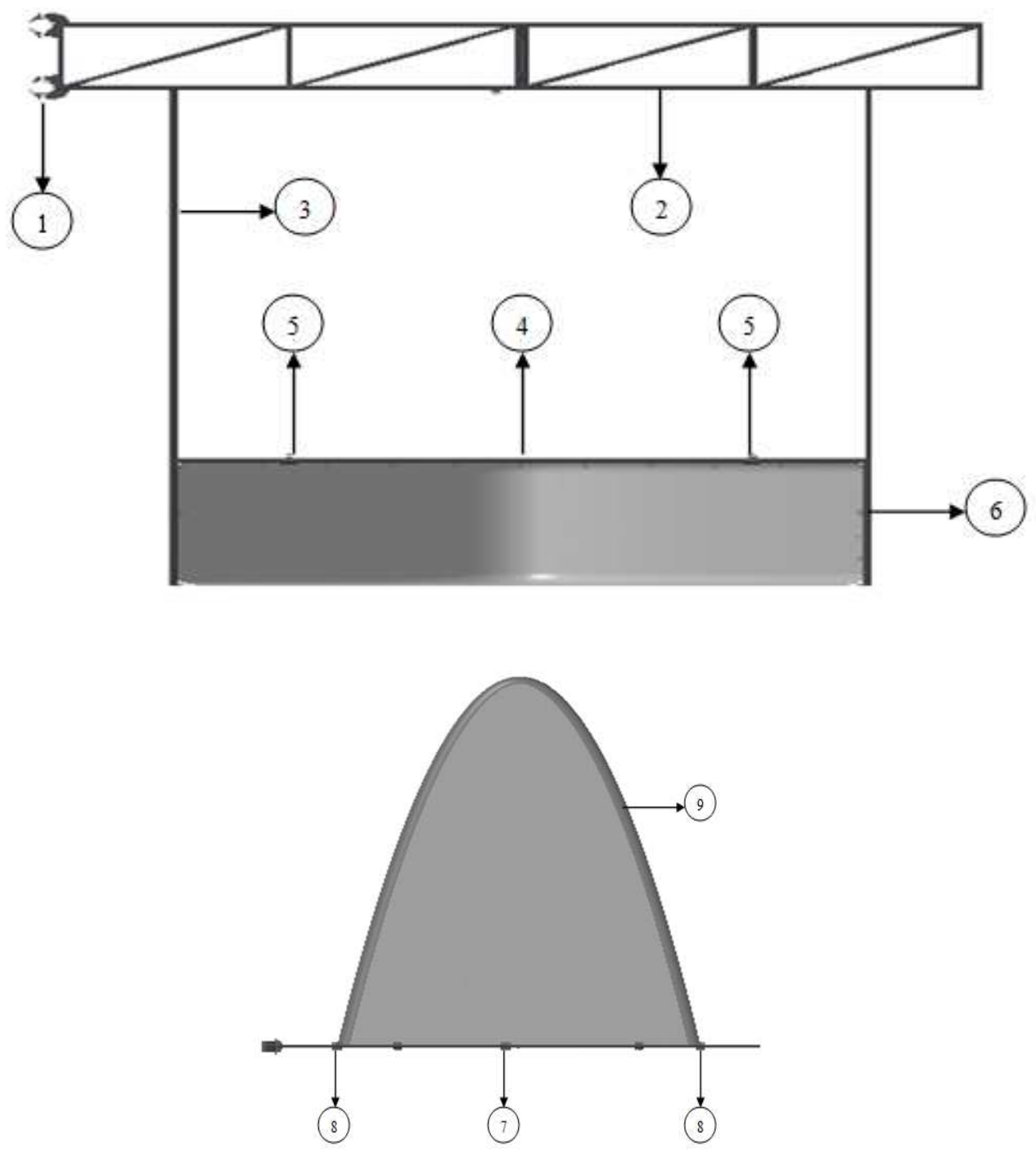

Figure 3. Components of tar balls collector 


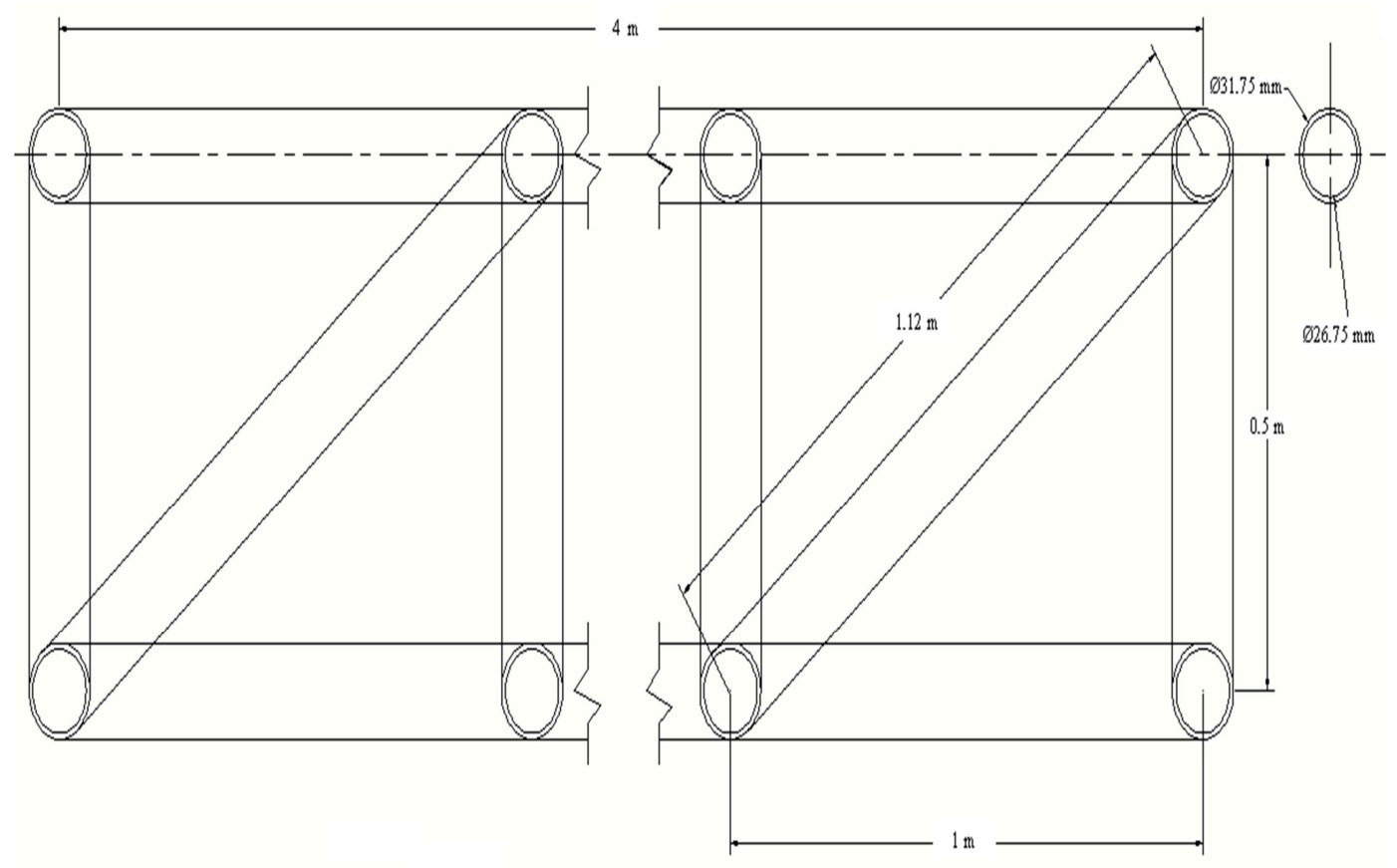

Figure 4. Technical drawing of long support

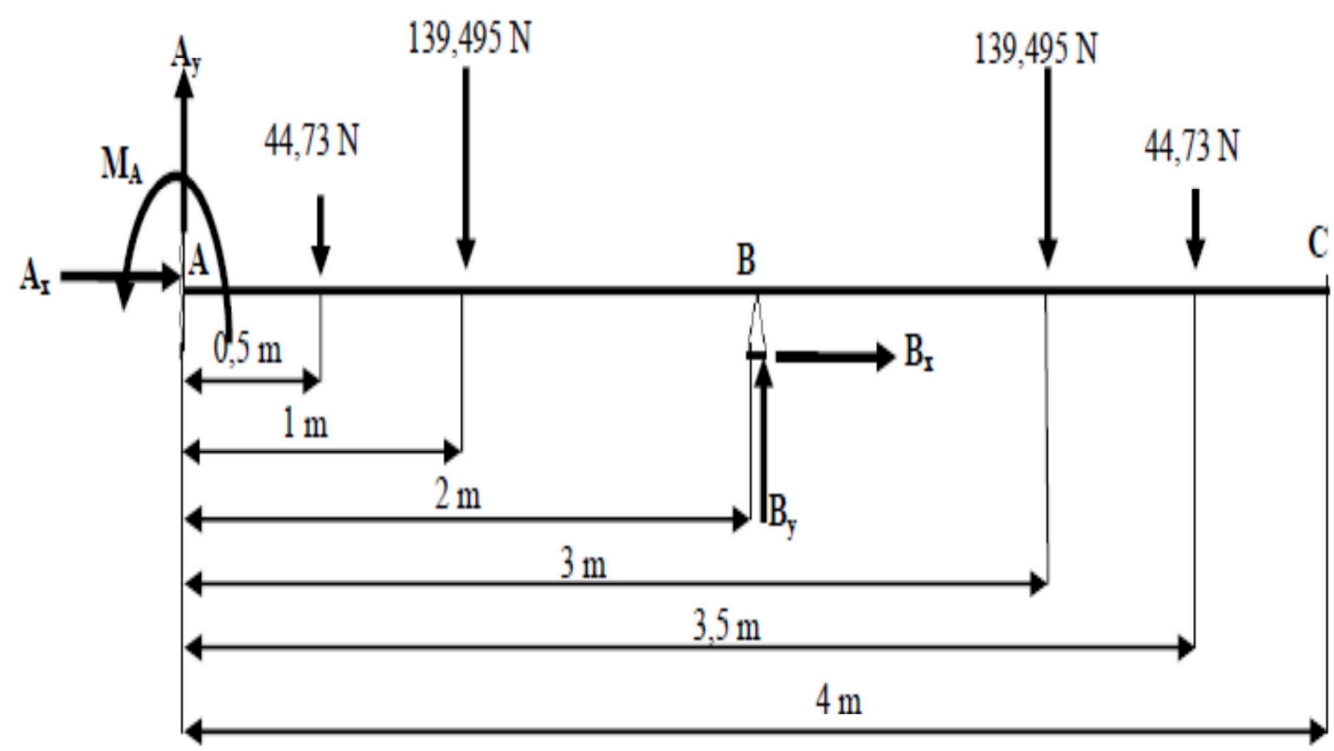

Figure 5. Free body diagram of the long support

$$
\begin{aligned}
& V=\left(\pi r_{l}^{2} t\right)-\left(\pi r_{d}^{2} t\right) \\
& m=\rho \times V \\
& W_{1}=m \times g \\
& \sum W=W_{1}+W_{2}+W_{3}
\end{aligned}
$$

Where :

$\mathrm{V}=$ volume $\left[\mathrm{m}^{3}\right]$

$\rho=$ density $\left[\mathrm{kg} / \mathrm{m}^{3}\right]$

$\mathrm{r}_{1}=$ outer radius $[\mathrm{m}]$

$\mathrm{r}_{\mathrm{d}}=$ inner radius $[\mathrm{m}]$

$\mathrm{t}=$ length of the support $[\mathrm{m}]$

$\mathrm{t}_{1}=4 \mathrm{~m} ; \mathrm{t}_{2}=0,5 \mathrm{~m} ; \mathrm{t}_{3}=1,12 \mathrm{~m}$ 
One of the external forces is the weight of the long support and the action line is located at the distance $2 \mathrm{~m}$. The others external forces are the weight of frame of the net and the action line are located at the distance of $0,5 \mathrm{~m}$ and $3,5 \mathrm{~m}$ from the hinge A. Three support reactions are on hinge A and three on hinge B. However horizontal reaction did not exist. The remaining unknown forces are four that make the structure to be one degree of static indeterminacy.

Force reaction on every point of analysis was shown on Fig 6. It was found out that the maximum force reaction was at point B in the middle of the long support. This result was the same as the result of the Atlas 2.0 software. The stress resultant was shown on Fig 7. The blue line represented the shear force and the red line represented the bending moment.

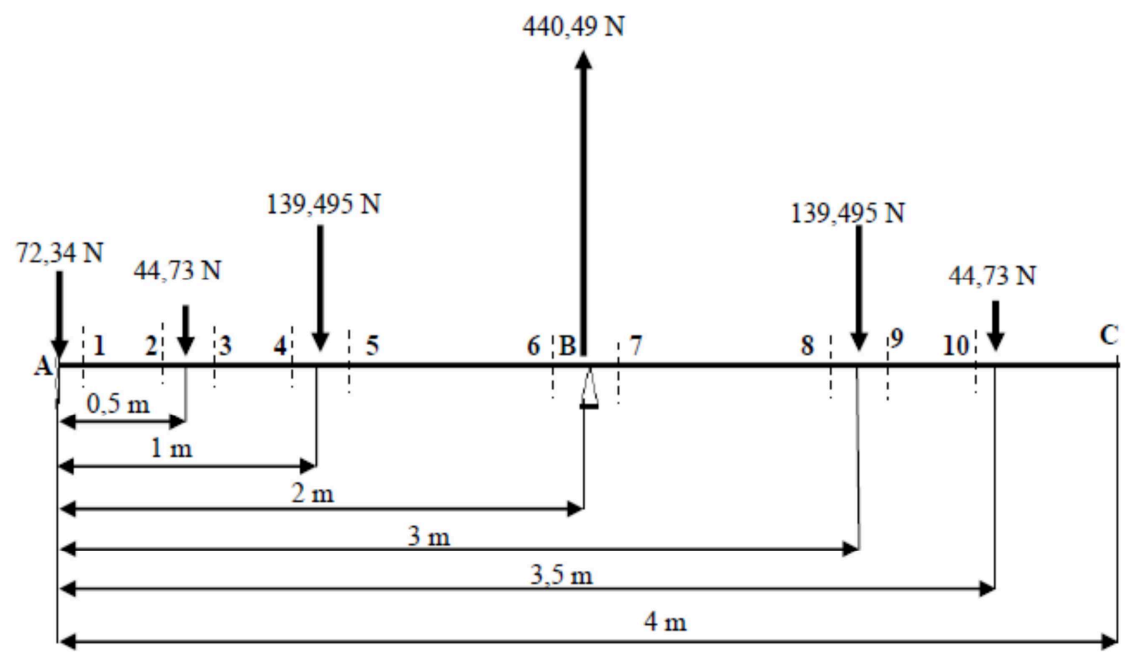

Figure 6. Force reaction

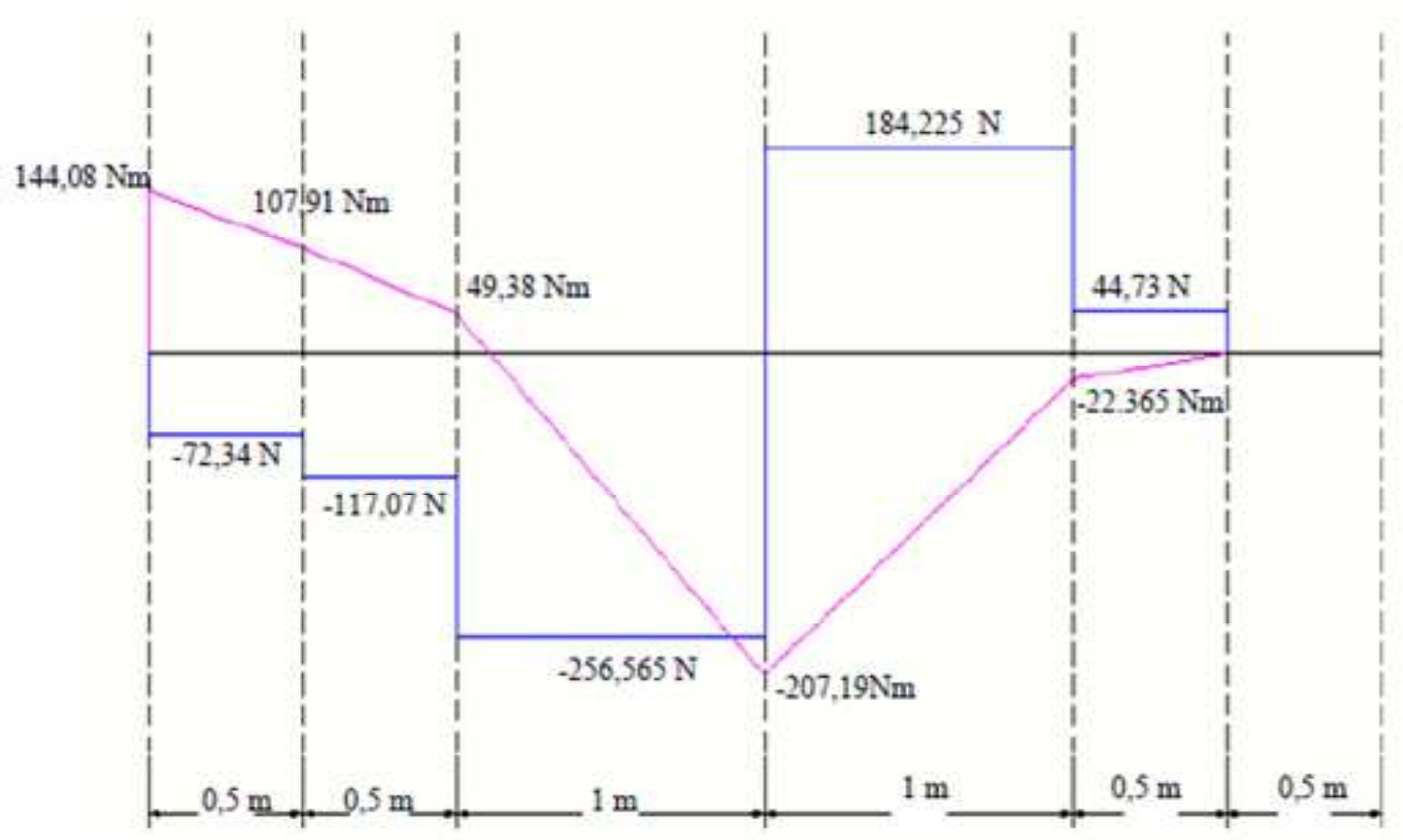

Figure 7. Stress resultant.

The safety factor of this design could be calculated using Eq. 5

$S_{f}=\frac{\sigma_{b \text { material }}}{\sigma_{b}}=\frac{2,05 \times 10^{8} \mathrm{~N} / \mathrm{m}^{2}}{0,87 \times 10^{8} \mathrm{~N} / \mathrm{m}^{2}}$

$S_{f}=2,37 \geq 2$ 


\section{Conclusion}

Mechanical analysis of the tar balls collector had been completed starting from the free body diagram and stress resultant. It showed that the safety factor of this tool is greater than 2. It fulfilled the standard for non critical design. This design could be applied as the alternative tool on the strategy for combating oil spill emergency response.

Further investigation on the dynamic analysis is necessary and also on site the testing of this equipment should be carried out in the future to determine the effect of current, wind, and tar balls dimension on the performance of mechanical recovery of this tool.

\section{References}

[1] Mukhtasor, Pencemaran Pesisir dan Laut, edisi I, Pradnya Paramita, Jakarta, 2007

[2] Masoudnia, K, Raisi, A, Aroujalian, A, Fathizadeh, M, Cross-flow microfiltration oil-in water emulsion using polyvinylidenefluoride membrane, Procedia Engineering Euromembrane Conference. 44 (2012) 1974-1976

[3] Chakrabarty, B., Ghoshal, A.K. Purkait, M.K., Cross-flow ultrafiltration of stable oil-in-water emulsion using polysulfone membranes, Chemical Engineering Journal. 165 Issue 2 (2010) 447456

[4] Monsour, Ben, L, Chalbi, S, Removal of oil from oil water emulsion using elektrofluotation process, Journal of Applied Electrochemistry. 36 (2006) 577-581

[5] Yuan, Jikang., Liu, Xiaogang., Akbulut, Ozge., Hu Junqing., Suib, Steven L., Kong, Jing., Stellacci, Francesco, Superwetting Nanowire membranes for selective absorption, Nature Nanotechnology. 3 (2008) 332-336

[6] McClimans, T., Leifer, I., Gjøsund, Svein H.,; Grimaldo, E.,; Per Daling, Leirvik, F., 2013, Pneumatic oil barriers: The promise of area bubble plumes, Proceedings of the Institution of Mechanical Engineers, Part M: Journal of Engineering for the Maritime Environment. 227 no. 1 (2013) 22-38 